RU Развитие иноязычных коммуникативных умений студентов технического вуза в процессе дистанционного обучения

Захарова О. О.

Аннотация. Цель исследования - представить обоснование способов развития иноязычных коммуникативных умений студентов технического вуза в условиях дистанционной образовательной среды. В статье описывается комплекс теоретико-методологических подходов, раскрывающих системные, компетентностные и деятельностные основы изучаемого процесса. Научная новизна определяется тем, что разработана система развития у будущих инженеров коммуникативных умений в дистанционном формате, предложен комплекс упражнений для организации работы студентов на занятиях по иностранному языку. В результате эксперимента получена положительная динамика в уровнях коммуникативных умений студентов экспериментальной группы.

\title{
EN Developing Technical Students' Foreign-Language Communicative Skills in the Course of Distance Teaching
}

\author{
Zakharova 0. 0.
}

\begin{abstract}
The article proposes methodology to develop technical students' foreign-language communicative competence in virtual educational environment. The author describes theoretical and methodological approaches that reveal systemic, competence-based and activity-based foundations of the process under study. Scientific originality of the paper is conditioned by the fact that the researcher introduces methodlogy to develop future engineers' foreign-language communicative skills in the course of distance teaching, suggests a set of foreign-language exercises for distance learners. Experiment results indicate increase in target students' communicative competence.
\end{abstract}

\section{Введение}

Компьютеризация, цифровизация сегодняшней жизни, изменение способов восприятия информации определяют динамику современной образовательной парадигмы. В образовательный процесс во многих вузах внедряются цифровые платформы образования, апробируются инновационные форматы к преподаванию разных дисциплин на основе информационных и мобильных технологий. Новые подходы к преподаванию иностранных языков также базируются на использовании информационно-коммуникационных технологий (далее - ИКТ) и предполагают пересмотр содержания и организационно-методических форм обучения, в том числе в режиме онлайн [7]. Стоит отметить, что события, связанные с распространением вируса COVID-19, остро актуализируют потребность во внедрении новых удаленных форматов организации работы студентов и обусловливают появление вопросов, связанных с методической организацией процесса преподавания иностранного языка с учетом специфики данной дисциплины. С точки зрения обучения иностранному языку особую эффективность представляет модульная событийно-ориентированная динамическая среда Moodle [2]. Рассматривая возможности организации цифрового пространства в обучении иностранному языку, в том числе с использованием Moodle, исследователи определяют следующие преимущества:

- свободный доступ к иноязычным аутентичным материалам, большому количеству информационных источников [Там же];

- самостоятельное управление студентами, собственным учебным процессом [4];

- комплексность ресурсов Moodle (лекции, семинары, тесты, чаты), что способствует организации аудиторной и внеаудиторной работы и развитию навыков студентов в разных видах речевой деятельности;

- возможность осуществления обратной связи с другими студентами и преподавателем, что особенно значимо при коммуникации на иностранном языке и осуществлении контроля за работой студента со стороны преподавателя.

Научная статья (original research article) । https://doi.org/10.30853/ped200131

( 2020 Авторы. 000 Издательство «Грамота» (๔ 2020 The Authors. GRAMOTA Publishers). Открытый доступ предоставляется на условиях лицензии СС ВY 4.0 (open access article under the CС BY 4.0 license): https://creativecommons.org/licenses/by/4.0/ 
Опираясь на данные возможности виртуальной среды обучения, многие исследователи описывают опыт применения дистанционного обучения и виртуальной среды Moodle в процессе преподавания разных аспектов иностранного языка. В работе А. М. Евсеевой Moodle раскрывается как платформа создания индивидуальной образовательной траектории в развитии аудитивных умений студентов, в рамках которой ими осуществляется выбор уровня сложности и вырабатывается собственная стратегия прослушивания [6]. Преимущества Moodle как платформы обучения студентов аудированию также рассматриваются Е. Ю. Скворцовой, П. Дж. Митчеллом [15]. Упражнения, направленные на развитие иноязычной письменной речи студентов, обозначены в исследовании О. П. Шабан [20].

Без сомнения, наличие живого общения особенно значимо в развитии коммуникативной компетенции обучающихся, при этом ИКТ должны быть дополнением к традиционному формату [8]. Анализ вышеупомянутых работ позволяет определить общую положительную оценку потенциала дистанционного обучения студентов иностранному языку и обозначить возможности Moodle в преподавании отдельных языковых аспектов. Однако на сегодняшний день отсутствуют работы, представляющие достаточное теоретическое обоснование и методическое описание организации устной иноязычной коммуникации студентов технического вуза в условиях дистанционного обучения. При строгой изоляции организация живого общения затруднена, следовательно, актуальность настоящей работы определяется необходимостью разработки теоретических основ и практических способов развития иноязычных коммуникативных навыков будущих инженеров в дистанционной образовательной среде.

Задачами исследования являются следующие:

- выделить иноязычные коммуникативные умения, необходимые будущим инженерам для осуществления успешной профессиональной деятельности, и определить особенности формирования данных умений в дистанционной среде;

- определить методологические основания для разработки и характеристики системы, направленной на развитие иноязычных коммуникативных умений у студентов технического вуза в дистанционном формате;

- разработать систему развития у студентов иноязычных коммуникативных умений в процессе дистанционного обучения, содержащую комплекс упражнений и диагностический аппарат для определения сформированности у студентов рассматриваемых умений;

- провести методический эксперимент по реализации предложенной системы, осуществить сравнительную характеристику полученных результатов на разных этапах экспериментальной работы и сделать выводы об эффективности предложенных способов.

В работе применялись такие методы исследования, как анализ научно-педагогической литературы, оценка опыта организации преподавания иностранных языков в дистанционном режиме, проектирование педагогической системы, опрос, тестирование, методы статистической обработки данных.

Теоретической базой работы являются исследования, посвященные изучению специфики организации дистанционного обучения иностранным языкам [3; 12; 19], организации преподавания данной дисциплины на платформе Moodle [5; 18]. Отдельные практические аспекты развития коммуникативных умений студентов раскрываются в исследовании Н. В. Худолей, где акцентируется внимание на осуществлении работы студентов в Moodle в режиме «Страница», материалы которой могут выступить основой для развития их навыков говорения [17]. Оптимизация процесса обучения студентов для развития их коммуникативных умений на базе Moodle как платформы, позволяющей вовлечь студентов в живую коммуникацию, также освещается в работе Е. А. Рубцовой [13].

Практическая значимость исследования определяется следующим: разработана система развития иноязычных коммуникативных умений у студентов технического вуза, которая может применяться в процессе преподавания иностранного языка в дистанционном режиме; представлен примерный комплекс упражнений, способствующих развитию коммуникативных умений будущего инженера, определен критериально-оценочный аппарат для диагностики уровня сформированности у студента иноязычных коммуникативных умений.

\section{Основная часть}

Раскроем теоретико-методологические основы исследования, в качестве которых выступает совокупность подходов. Наше обращение к системному подходу обусловлено тем, что исследуемый процесс является компонентом цифровой образовательной среды вуза. Данный процесс направлен на развитие у будущих инженеров коммуникативных умений в дистанционном режиме и представлен нами как системный комплекс.

Применение компетентностного подхода продиктовано тем, что основной целью обучения иностранному языку в неязыковом вузе, согласно ФГОС, является формирование у студентов универсальных компетенций, заключающихся в способности реализовать деловую коммуникацию в устной и письменной формах на иностранном языке. Коммуникативные умения являются составной частью коммуникативной компетенции студента.

Использование коммуникативного подхода определяет обращение к содержательному наполнению коммуникативных умений студента. Анализ литературы позволяет выделить группы данных умений: умения, позволяющие решать информационно-содержательные задачи коммуникации, умения, определяющие стратегию взаимодействия, и умения, способствующие взаимному восприятию сторон коммуникации друг другом [14]. Данные группы соотносятся с видами коммуникативных умений, обозначенных Г. М. Андреевой (умения межличностной коммуникации, межличностного взаимодействия и межличностного восприятия) [16]. 
Опираясь на рассмотренную классификацию, учитывая виды деятельности инженера, выделенные в работе К. М. Иноземцевой [10, с. 77], а также ссылаясь на специфику дисциплины «Иностранный язык», определим набор коммуникативных умений, которые должны быть сформированы у будущего инженера (Таблица 1).

Таблица 1. Иноязычные коммуникативные умения, формируемые у студента технического вуза

\begin{tabular}{|c|c|c|}
\hline Умения устной коммуникации & $\begin{array}{c}\text { Умения межличностного } \\
\text { восприятия }\end{array}$ & $\begin{array}{c}\text { Умения организации } \\
\text { обратной связи }\end{array}$ \\
\hline $\begin{array}{l}\text { владение студентом речевыми сред- } \\
\text { ствами, позволяющими ему участво- } \\
\text { вать в: } \\
\text { - научно-исследовательской работе } \\
\text { (написание статей, участие в научных } \\
\text { конференциях); } \\
\text { - проектной деятельности (разработ- } \\
\text { ка технических спецификаций и пр.); } \\
\text { - описании производственно- } \\
\text { технологических процессов; } \\
\text { - решении организационно- } \\
\text { управленческих вопросов; } \\
\text { - осуществлении иноязычной ком- } \\
\text { муникации в ходе аудиторной/ } \\
\text { внеаудиторной работы }\end{array}$ & $\begin{array}{l}\text { - умение слушать собеседника; } \\
\text { - умение интерпретировать полу- } \\
\text { ченную информацию с учетом ком- } \\
\text { муникативной ситуации; } \\
\text { - умение корректно определять } \\
\text { стратегию взаимодействия }\end{array}$ & $\begin{array}{l}\text { - } \text { умение отвечать на вопросы собе- } \\
\text { седника; } \\
\text { - умение выстраивать конструктив- } \\
\text { ный диалог в деловом общении; } \\
\text { - умение презентовать результаты } \\
\text { собственной исследовательской работы; } \\
\text { - умение описывать и обсуждать } \\
\text { производственные вопросы, техноло- } \\
\text { гические процессы, техническую до- } \\
\text { кументацию; } \\
\text { - умение обсуждать актуальные про- } \\
\text { блемы, выражать свою точку зрения }\end{array}$ \\
\hline
\end{tabular}

Использование деятельностного подхода позволяет охарактеризовать деятельностный характер исследуемого процесса, определяя роль преподавателя как консультанта, стратега, партнера по общению в дистанционной среде [11], раскрывая интерактивную направленность взаимодействия субъектов, в ходе которого обучение коммуникации расширяется во взаимодействии «студент-преподаватель», «студент-студент», «студент-аудитория», «студент-компьютер» [9, с. 65]. Деятельность субъектов данного процесса осуществляется в активных форматах взаимодействия в дистанционном режиме.

На основе данной теоретико-методологической базы разработана система развития иноязычных коммуникативных умений у студентов технического вуза. Мотивационный блок системы определяет стратегию стимулирования активной работы студентов дистанционно. Отталкиваясь от мысли, что мотивация студентов технического вуза к изучению иностранного языка включает профессионально значимые (профессиональное общение, понимание технических документов и пр.) и профессионально незначимые мотивы (коммуникация на иностранном языке) [1], учитывая специфику дисциплины «Иностранный язык в профессиональной деятельности», особенности преподавания в дистанционном формате, мы обозначили направления мотивирования студента:

- побуждение студентов к речевой коммуникации на иностранном языке в ходе аудиторной и внеаудиторной работы;

- раскрытие роли английского языка как важного инструмента в профессиональной коммуникации в дистанционном режиме;

- побуждение студентов к самостоятельному языковому развитию.

Реализации данных мотивационных направлений способствовал ряд мероприятий:

- использование возможностей мессенджеров и социальных сетей для организации быстрой обратной связи со студентами (по выбору обучающихся);

- систематическая организация работы студентов с аутентичными видео- и аудиоресурсами профессиональной и общей направленности на актуальные темы;

- использование игровых технологий, активирующих коммуникативные умения студентов, в дистанционном формате;

- применение цифровых средств визуализации (иллюстрации, интернет-мемы, инфографика, сервисы визуализации (Mindmap, Quizlet, Classtoolsnet)).

Ресурсный блок системы задает организационные характеристики и определяет содержательное наполнение изучаемого процесса, а также раскрывает методический аппарат осуществления работы со студентами в дистанционном пространстве. В рамках компонента разработан комплекс упражнений, направленный на формирование у студентов заданных коммуникативных умений. Предлагаемый комплекс построен, исходя из содержания программы дисциплины «Иностранный язык» и возможностей работы студентов в дистанционном режиме. Стоит обозначить, что разработка комплекса упражнений осуществлялась в условиях невозможности очной аудиторной работы со студентами, поэтому оптимальной моделью обучения являлся следующий вариант смешанного обучения: аудиторная работа в режиме видеосвязи с академической группой студентов с привлечением комплекса интернет-ресурсов и самостоятельная работа студентов на платформе Moodle. Учитывая особенности организации процесса дистанционного обучения, представим пример комплекса упражнений, разработанного для дистанционного обучения по дисциплине «Иностранный язык» для студентов первого курса (Таблица 2). 
Таблица 2. Вариант комплекса упражнений для развития коммуникативных умений студента технического вуза

\begin{tabular}{|c|c|c|}
\hline $\begin{array}{c}\text { Тематические } \\
\text { разделы }\end{array}$ & Примеры упражнений & $\begin{array}{c}\text { Используемые } \\
\text { методы, приемы работы }\end{array}$ \\
\hline \multicolumn{3}{|c|}{ Computers } \\
\hline $\begin{array}{l}\text { The Role of Computers } \\
\text { in People's Life }\end{array}$ & $\begin{array}{l}\text { Расскажите о роли компьютера в вашей собственной } \\
\text { жизни (по представленному плану) }\end{array}$ & $\begin{array}{l}\text { Презентация Реcha Kucha, ответы } \\
\text { на вопросы студентов и преподава- } \\
\text { теля в чате и видеобеседе }\end{array}$ \\
\hline $\begin{array}{l}\text { Modern Computers. } \\
\text { Computer Problems }\end{array}$ & $\begin{array}{l}\text { Выберите одну из ситуаций (например: You have done } \\
\text { important work on the computer. Suddenly it switches off. } \\
\text { Ask your groupmate for a piece of advice) }\end{array}$ & $\begin{array}{l}\text { Мозговой штурм в группе, обо- } \\
\text { значение вариантов решения про- } \\
\text { блемы в чате. Парная диалогическая } \\
\text { работа }\end{array}$ \\
\hline $\begin{array}{l}\text { Conditional Sentences, } \\
\text { II Type }\end{array}$ & $\begin{array}{l}\text { Просмотрите видеофрагмент “A Bad Day”, перечислите } \\
\text { действия героя видео. Что произошло бы иначе, если } \\
\text { бы он не совершил данные действия? }\end{array}$ & $\begin{array}{l}\text { Работа с видео в режиме «без зву- } \\
\text { ка», коммуникативно-граммати- } \\
\text { ческий практикум в режиме онлайн- } \\
\text { конференции }\end{array}$ \\
\hline $\begin{array}{l}\text { Computers versus } \\
\text { Human Beings }\end{array}$ & $\begin{array}{l}\text { Определите возможности компьютера и человека } \\
\text { в разной деятельности: научной, производственной, } \\
\text { коммуникативной, развлекательной. Представьте свои } \\
\text { аргументы за и против }\end{array}$ & $\begin{array}{l}\text { Представление аргументов с помо- } \\
\text { щью Роwer Рoint, участие в группо- } \\
\text { вой видеодискуссии / представле- } \\
\text { ние собственных аргументов в при- } \\
\text { ложении vTime }\end{array}$ \\
\hline \multicolumn{3}{|c|}{ Materials in Engineering } \\
\hline Modal Verbs Practice & $\begin{array}{l}\text { Прочитайте утверждения “The Rules of Life in the UK” } \\
\text { (например: It is obligatory to close all the shops on Sun- } \\
\text { days). Составьте свои предположения с использова- } \\
\text { нием модальных глаголов (must / mustn't / have } \\
\text { to / don't have to). Задайте аналогичные вопросы про } \\
\text { жизнь в нашей стране }\end{array}$ & $\begin{array}{l}\text { Парная, фронтальная работа, работа } \\
\text { в чате видеоконференции }\end{array}$ \\
\hline Composite Materials & $\begin{array}{l}\text { Imagine you are at the lecture on the topic “Composite } \\
\text { Materials in Engineering” (роли для студентов: лектор } 1 \\
\text { (properties of composite materials), лектор } 2 \text { (application of } \\
\text { composite materials in engineering), студент 1-3 (ask ques- } \\
\text { tions on the composite materials in machine-building) и пр.). } \\
\text { Прочитайте текст диалога между двумя студентами } \\
\text { “Composite Ceramics”, ответьте на предложенные во- } \\
\text { просы. Составьте собственный диалог с целью убедить } \\
\text { вашего друга не пропускать важную лекцию }\end{array}$ & $\begin{array}{l}\text { Ролевая игра в режиме онлайн-кон- } \\
\text { ференции. Самостоятельная работа } \\
\text { студентов в режиме «Страница». } \\
\text { Диалог в онлайн-режиме }\end{array}$ \\
\hline \multicolumn{3}{|c|}{ Transportation } \\
\hline Ways of Transportation & $\begin{array}{l}\text { Прослушайте аудиозапись “Тор Gear Challenge”. Вы- } \\
\text { полните задания теста. Определите преимущества } \\
\text { и недостатки разных транспортных средств. Сообщите } \\
\text { о них собеседнику. Передайте мнение собеседника } \\
\text { всей группе }\end{array}$ & $\begin{array}{l}\text { Самостоятельная работа в Moodle } \\
\text { в режиме «Тест». Парная работа } \\
\text { в мессенджере. Фронтальная работа } \\
\text { в режиме видеоконференции }\end{array}$ \\
\hline Cars. Car Components & $\begin{array}{l}\text { Напишите объявление о продаже автомобиля. Озна- } \\
\text { комьтесь с объявлениями других студентов. Выберите } \\
\text { автомобиль, аргументируйте. Пообщайтесь с продав- } \\
\text { цом автомобиля }\end{array}$ & $\begin{array}{l}\text { Самостоятельная работа студентов } \\
\text { в Moodle в режиме «Страница»/ } \\
\text { «Эссе». Групповое-парное обсужде- } \\
\text { ние в режиме видеоконференции }\end{array}$ \\
\hline $\begin{array}{l}\text { Business } \\
\text { Communication }\end{array}$ & $\begin{array}{l}\text { Прочитайте ситуацию. Составьте телефонный разго- } \\
\text { вор. You work for Engineering Company. You need to ask } \\
\text { delivery service to collect a package from the company. } \\
\text { Call and solve the problem, have your office address and } \\
\text { details about the package ready to give them. Ask about } \\
\text { the price. Record your dialogue }\end{array}$ & $\begin{array}{l}\text { Парная работа студентов. Ведение } \\
\text { аудиозаписи диалога }\end{array}$ \\
\hline $\begin{array}{l}\text { Car History. } \\
\text { Assembly Line }\end{array}$ & $\begin{array}{l}\text { Изучите таймлайн “The History of Automobiles” In- } \\
\text { vention”. Обозначьте пропущенную информацию. } \\
\text { Задайте вопросы и найдите ответы для них в Интерне- } \\
\text { те. Представьте найденную информацию }\end{array}$ & $\begin{array}{l}\text { Самостоятельная поисковая работа } \\
\text { студентов. Групповое обсуждение } \\
\text { в режиме видеоконференции }\end{array}$ \\
\hline
\end{tabular}

В основе предложенного комплекса заложены принципы междисциплинарности, коммуникативной ситуативности и эмпатийного взаимодействия субъектов системы. Ключевыми типами упражнений, реализуемых в дистанционном формате, выступают следующие:

1) условно-речевые упражнения:

- составление вопросов по прочитанному тексту/статье (Make up three-five questions about A. Einstein's life and work, ask your questions to other student);

- представление рассказа по заданному плану (Tell about the role of computers in your life: mention the role of computers in modern life, in your daily routine, the characteristics your personal computer should possess);

- составление аннотации к тексту с использованием ключевых слов темы (Use the key words to speak about materials in engineering); 
- подготовка высказывания на основе зрительного образа с опорой на заданный лексический материал (Watch the video, paying attention to the actions of the character. Look at the verbs. Put them in chronological order according to the video, make up sentences about the character);

2) речевые упражнения:

- «мозговой штурм» в группе студентов (Brainstorm some ideas: what items are made of copper, bronze, aluminum, steel, tin. Tell or write your sentences in the chat);

- презентация собственного развернутого сообщения с демонстрацией Power Point или иных изображений (Think about the future prospects of the development of your university. Be ready to give a full answer and present it. Use images or Power Point);

- проведение онлайн-дискуссии (Present your arguments for and against computer excellence over a human being);

- упражнения игрового, творческого характера на основе решения коммуникативной ситуации (You have a car for sale. Make up and present your advertisement. Be ready to answer the potential clients' questions);

3) интерактивные упражнения:

- групповое обсуждение в чате, в ходе видеоконференции (Present any piece of news you've recently read. Discuss it with the group);

- парное обсуждение в мессенджерах, чате (Look at the list of questions, learn your groupmate's opinion about them);

- диалогическая работа по заданной коммуникативной ситуации (Make up a dialogue: you meet your groupmate at the timetable. Persuade him or her not to miss an important lecture).

Рефлексивный блок связан с оцениванием и получением обратной связи от студентов по поводу результативности проводимой работы. Для диагностики уровня сформированности выделенных коммуникативных умений студента использовались следующие критерии и показатели:

- когнитивный - владение студентом речевыми средствами для осуществления коммуникации в ходе аудиторной и внеаудиторной работы с преподавателем и студентами, для возможного осуществления научноисследовательской, проектной, технологической, организационно-управленческой профессиональной деятельности;

- перцептивный - способность к корректному восприятию англоязычной речи на слух, ее интерпретации, определению собственной реакции в сложившейся коммуникативной ситуации;

- операциональный - способность к корректному реагированию на речь собеседника, представлению собственного мнения, аргументации в процессе личной и профессионально-направленной коммуникации.

Мы также определили три уровня сформированности коммуникативных умений у будущих инженеров (Таблица 3).

Таблица 3. Уровни сформированности иноязычных коммуникативных умений у студентов

\begin{tabular}{|c|c|}
\hline Уровни & Характеристика \\
\hline Базовый & $\begin{array}{l}\text { - недостаточное владение студентом речевыми средствами для осуществления коммуникации } \\
\text { в ходе аудиторной и внеаудиторной работы, а также взаимодействия в ходе предлагаемых ком- } \\
\text { муникативных ситуаций, касающихся разных видов профессиональной деятельности; } \\
\text { - низкая способность к корректному восприятию англоязычной речи на слух, ее неверная ин- } \\
\text { терпретация; } \\
\text { - недостаточное/некорректное определение собственной реакции в исходной коммуникатив- } \\
\text { ной ситуации; } \\
\text { - низкая способность студента к корректной реакции на речь собеседника, представлению } \\
\text { своей точки зрения и ее аргументации в процессе коммуникации }\end{array}$ \\
\hline Адаптивный & $\begin{array}{l}\text { - владение студентом основными речевыми средствами для осуществления коммуникации } \\
\text { в ходе аудиторной и внеаудиторной работы, а также в процессе решения репродуктивных ком- } \\
\text { муникативных ситуаций, касающихся разных видов профессиональной деятельности; } \\
\text { - способность студента к корректному восприятию ключевых элементов англоязычной речи } \\
\text { на слух, ее верная интерпретация; } \\
\text { - способность студента адаптировать исходную коммуникативную ситуацию для выражения } \\
\text { собственной позиции; } \\
\text { - способность студента к корректной реакции на речь собеседника, представлению своей точ- } \\
\text { ки зрения и ее аргументации в процессе подготовленной коммуникативной ситуации }\end{array}$ \\
\hline Высокий & $\begin{array}{l}\text { - хорошее владение студентом речевыми средствами для осуществления коммуникации в ходе } \\
\text { аудиторной и внеаудиторной работы, а также в процессе решения нестандартных коммуника- } \\
\text { тивных ситуаций, касающихся разных видов профессиональной деятельности; } \\
\text { - хорошая способность студента к корректному детальному восприятию англоязычной речи } \\
\text { на слух, ее верная интерпретация; } \\
\text { - способность студента корректно определять собственную позицию в исходной коммуника- } \\
\text { тивной ситуации с привлечением достаточного количества речевых средств для ее выражения; } \\
\text { - хорошая способность студента к корректной реакции на речь собеседника, представлению } \\
\text { своей точки зрения и ее аргументации в процессе живой коммуникативной ситуации }\end{array}$ \\
\hline
\end{tabular}

Проверка эффективности разработанных способов развития у студентов коммуникативных умений осуществлялась в ходе методического эксперимента, длившегося в течение одного семестра и проведенного среди 47 студентов-первокурсников Трехгорного технологического института. 
Не акцентируя внимания на ходе эксперимента, приведем сравнительную характеристику данных, полученных на разных его этапах (Таблица 4).

Таблица 4. Сравнение данных экспериментальной работы

\begin{tabular}{|c|c|c|c|c|c|c|c|c|c|}
\hline \multirow[b]{3}{*}{ 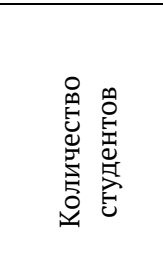 } & \multicolumn{3}{|c|}{ Входной срез } & \multicolumn{3}{|c|}{ Промежуточный срез } & \multicolumn{3}{|c|}{ Итоговый срез } \\
\hline & \multicolumn{9}{|c|}{ Уровни (\%) } \\
\hline & 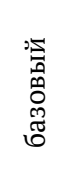 & 茎 & 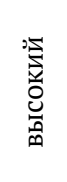 & 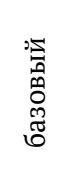 & 茎 & 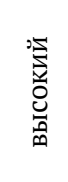 & 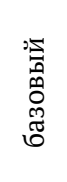 & 茎 & 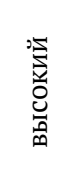 \\
\hline ЭГ (26 чел.) & 43,4 & 46,1 & 10,5 & 34,8 & 44,7 & 20,5 & 28,0 & 35,6 & 36,4 \\
\hline КГ (21 чел.) & 40,4 & 45,9 & 13,7 & 45,5 & 43,8 & 10,7 & 38,0 & 45,5 & 16,5 \\
\hline
\end{tabular}

В качестве диагностических инструментов выступали практические коммуникативно-направленные задания, наблюдение за ходом самостоятельной и аудиторной работы студента, коммуникативные ситуации, тесты, реализованные в дистанционном режиме. Сравнительная характеристика данных указывает на повышение уровня владения студентом коммуникативными умениями: количество студентов с высоким уровнем в экспериментальной группе (ЭГ) увеличилось на 25,9\%. В ходе проводимой работы студенты отмечали комфортные условия для коммуникации в дистанционной среде, удобство доступа к необходимым интернет-ресурсам и материалам на платформе Moodle, интерес к использованию мобильных приложений и дистанционных ресурсов, которые способствуют повышению уровня владения языком. Особенно значимыми в ходе реализации системы показали себя интерактивные упражнения, которые позволяют развивать всю совокупность обозначенных коммуникативных умений. Такие возможности дистанционного формата работы, как легкий доступ к учебным материалам, быстрый обмен информацией, сплочение коллектива студентов в ходе занятия позволяют организовать обратную связь преподавателя с каждым студентом и снимать психологические барьеры, возникающие в процессе говорения на иностранном языке.

Полученные результаты позволяют заявлять, что положительная динамика в процессе развития иноязычных коммуникативных умений будущих инженеров в дистанционном режиме обусловлена реализацией группы педагогических условий:

- материально-технических - свободный доступ всех участников системы к проводимым занятиям в режиме видеоконференции (наличие технических средств, доступа к Интернет, установка требуемого программного обеспечения и приложений), что обеспечивает качественную и быструю коммуникацию в ходе организуемой работы;

- методико-организационных - создание имитации ситуаций иноязычного личного и профессионального взаимодействия (побуждение студентов к парной работе в дистанционном режиме над коммуникативными ситуациями, использование вариативных форм работы, побуждающих студентов к активному говорению и слушанию собеседников: имитация телефонного разговора, дискуссия в приложении виртуальной реальности, устные презентации с опорой на визуальную основу);

- личностно-коммуникативных - тьюторское сопровождение процесса развития коммуникативных умений студентов (привлечение студента к активному взаимодействию, индивидуальное консультирование его работы с помощью мессенджеров, социальных сетей).

\section{Заключение}

Теоретический анализ позволил определить умения устной коммуникации, умения межличностного восприятия и умения организации обратной связи как группы иноязычных коммуникативных умений, необходимых будущим инженерам для осуществления успешной профессиональной деятельности. В ходе исследования обосновано использование системного, компетентностного и деятельностного подходов как основы построения системы, нацеленной на развитие иноязычных коммуникативных умений у студентов технического вуза в дистанционном формате. Предложенная система раскрывается как совокупность мотивационного, ресурсного и рефлексивного компонентов. В рамках системы обозначены направления мотивирования студентов к активному взаимодействию в дистанционной среде, предложен комплекс практических упражнений, способствующий формированию у студентов иноязычных коммуникативных умений с учетом особенностей обучения в дистанционном режиме, и раскрыт критериально-оценочный аппарат для определения уровня сформированности у студентов рассматриваемых умений. Комплекс упражнений, примененный в ходе реализации системы, включает условно-речевые, речевые и интерактивные упражнения на основе оптимального для дистанционной среды методического аппарата (самостоятельная работа с использованием инструментов Moodle, парная работа в чате, диалогичная работа в онлайн-конференции, коммуникативная работа студентов с помощью мобильных приложений и пр.). 
Способность к осуществлению живого иноязычного личностно и профессионально-направленного общения определяет интерес студента к развитию собственного языкового уровня, а также составляет требование перспективных работодателей. Несмотря на возникающие барьеры организации процесса развития коммуникативных умений у студентов, дистанционный формат работы отличает внедрение новых вариативных методов взаимодействия со студентами, быстрый доступ к материалам занятий, свобода выбора студентами способа взаимодействия с преподавателем и студентами и дополнительные возможности визуализации коммуникативных ситуаций, что особенно значимо в работе со студентами поколения Z. Разработанная система развития иноязычных коммуникативных умений у студентов технического вуза в формате дистанционного обучения позволяет оптимизировать процесс обучения иностранному языку, обеспечивая прирост в уровнях сформированности данных умений у будущего инженера.

Направлением дальнейшей работы нами рассматривается организация процесса развития у студентов технического вуза иноязычных коммуникативных умений с привлечением иных методов дистанционной работы.

\section{Список источников}

1. Авдеев А. П. Мотивы изучения иностранного языка // Educational Technology \& Society. 2008. T. 11 . № 4. C. 310-322.

2. Азизова С. М. Об опыте использования открытой образовательной среды для обучения иностранному языку в вузе // Гуманитарные науки и образование. 2019. Т. 10. № 3 (39). С. 7-10.

3. Апальков В. Г. Использование современных средств обучения и интернет-технологий в обучении иностранным языкам // Открытое образование. 2013. № 6 (101). С. 71-75.

4. Володина Д. В., Юрьева Ю. С. Возможности применения электронного курса при обучении иностранному языку в техническом вузе (на базе электронной платформы Moodle) // Современные исследования социальных проблем. 2017. Т. 8. № 2-2. С. 53-62.

5. Воног В. В. Управление профессиональным развитием личности на основе информационных технологий в обучении иностранному языку // Вестник Московского государственного лингвистического университета. Образование и педагогические науки. 2018. № 6 (814). С. 41-52.

6. Евсеева А. М. Реализация индивидуальной образовательной траектории для развития аудитивных умений студентов неязыкового вуза в условиях смешанного обучения // Филологические науки. Вопросы теории и практики. 2019. Т. 12. № 2. С. 250-254. DOI: 10.30853/filnauki.2019.2.54.

7. Жавнер Т. В., Тахавеева Ю. В. Информатизация обучения иностранному языку с развитием межкультурной профессиональной коммуникативной компетенции у студентов бакалавриата инженерных специальностей // Вестник Кемеровского государственного университета. 2015. № 2-3 (62). С. 46-51.

8. Засухина А. С. Использование дистанционных технологий в обучении грамматике английского языка на базе образовательной платформы SAKAI // Crede Experto: транспорт, общество, образование, язык. 2018. № 2. C. 290-298.

9. Зорина О. С. Формирование коммуникативной компетенции будущих инженеров [Электронный ресурс]: дисс. ... к. пед. н. Н. Новгород, 2016. URL: https://www.kantiana.ru/upload/iblock/7b9/zorina_o_s_dissertatsiya.pdf (дата обращения: 19.07.2020).

10. Иноземцева К. М. Анализ современных требований к владению иностранным языком специалистами инженерно-технических профилей // Образование и наука. 2017. Т. 19. № 6. С. 71-90.

11. Пасечник Т. Б., Карякина Е. М. Опыт использования мини-сайта при дистанционном обучении грамматике английского языка // Педагогика. Вопросы теории и практики. 2020. Т. 5. № 2. С. 190-195. DOI: 10.30853/pedagogy.2020.2.11.

12. Присмотрова О. С. Формирование профессионально ориентированной иноязычной коммуникативной компетенции магистрантов нелингвистического вуза [Электронный ресурс]: дисс. ... к. пед. н. Н. Новгород, 2018. URL: https://lunn.ru/media/upr_NIR/dis_sov/02/prismotrova/dissertaciya_prismotrovoy_ot_07.02.2018_1.pdf (дата обращения: 25.07.2020).

13. Рубцова Е. А. Формирование коммуникативной компетенции студентов в процессе обучения иностранному языку на базе LMS Moodle // Вестник Самарского университета. История, педагогика, филология. 2018. T. 24. № 2. C. 63-69.

14. Сараева В. В. Формирование коммуникативных умений студентов вуза // Казанский педагогический журнал. 2010. № 2 (80). С. 22-28.

15. Скворцова Е. Ю., Митчелл П. Дж. Разработка электронного курса по обучению аудированию в информационной образовательной среде Moodle // Язык и культура. 2016. № 2 (34). С. 177-187.

16. Хайрутдинова И. В. Иноязычные коммуникативные умения как компонент общепрофессиональной компетенции руководителя органов внутренних дел // Педагогический журнал. 2017. Т. 7. № 1А. С. 107-116.

17. Худолей Н. В. Методика использования инструментария LMS Moodle для развития навыков коммуникации на иностранном языке у студентов неязыкового вуза // Филологические науки. Вопросы теории и практики. 2019. Т. 12. № 10. С. 385-390. DOI: 10.30853/filnauki.2019.10.81.

18. Хусаинова А. А. Педагогические условия использования системы Moodle в организации самостоятельной работы при обучении иностранному языку студентов экономических специальностей [Электронный реcypc]. URL: https://cyberleninka.ru/article/n/pedagogicheskie-usloviya-ispolzovaniya-sistemy-moodle-v-organizatsiisamostoyatelnoy-raboty-pri-obuchenii-inostrannomu-yazyku/viewer (дата обращения: 21.07.2020). 
19. Чалкова В. В. Дистанционное обучение иностранному языку: организация взаимодействия и техническая реализация // Вестник Пермского национального исследовательского политехнического университета. Проблемы языкознания и педагогики. 2016. № 1. С. 127-135.

20. Шабан О. П. Опыт применения информационно-коммуникационных технологий в обучении немецкому языку [Электронный ресурс]. URL: https://elib.bsu.by/bitstream/123456789/233433/1/Шабан_БГУ_ФСК_2019.pdf (дата обращения: 19.07.2020).

\section{Информация об авторах | Author information}

RU Захарова Ольга Олеговна ${ }^{1}$, к. пед. н.

${ }^{1}$ Трехгорный технологический институт -

филиал Национального исследовательского ядерного университета

«Московский инженерно-физический институт»

EN Zakharova Olga Olegovna ${ }^{1}, \mathrm{PhD}$

${ }^{1}$ Trekhgorny Institute of Technology (Branch)

of National Research Nuclear University “Moscow Engineering Physics Institute”

10sja90@bk.ru

\section{Информация о статье | About this article}

Дата поступления рукописи (received): 22.07.2020; опубликовано (published): 30.10.2020.

Ключевые слова (keywords): иноязычные коммуникативные умения; дистанционное обучение; технический вуз; теоретико-методологические подходы; foreign-language communicative skills; distance learning; technical higher school; theoretical and methodological approaches. 